ESJ Humanities

\title{
Screencast Video Feedback and its Implication on English as a Foreign Language (EFL) Writing
}

\author{
Nato Pachuashvili \\ $\mathrm{PhD}$ candidate of Education Sciences \\ International Black Sea University, Georgia
}

Doi:10.19044/esj.2021.v17n33p66

Submitted: 03 August 2021

Accepted: 23 August 2021

Published: 30 September 2021
Copyright 2021 Author(s)

Under Creative Commons BY-NC-ND

4.0 OPEN ACCESS

Cite As:

Pachuashvili N. (2021). Screencast Video Feedback and its Implication on English as a

Foreign Language (EFL) Writing. European Scientific Journal, ESJ, 17 (33), 66. https://doi.org/10.19044/esj.2021.v17n33p66

\begin{abstract}
Providing feedback to students' written work has always been a challenging experience for English as a foreign language (EFL) teachers and learners. High-quality feedback promotes students' engagement in learning processes and enhances writing performance. Traditional written corrective feedback has often been criticized for not being able to achieve its purpose. 21st-century technological development brought the necessity to provide audio and video feedback through screencast technology. The letter enables EFL teachers to provide multimodal feedback by recording the teacher's screen while commenting on a student's written work. Although there have been some studies conducted in the field of oral feedback via screencast, video feedback is still relatively new in many educational settings. For this reason, the paper aims to provide a brief overview of screencast video feedback, potential affordances and challenges faced by EFL teachers and learners. For this article, recent research studies have been collected to review the use of screencast feedback in EFL class and discuss its implications on EFL students' writing. Furthermore, the paper provides an overview of the most widely-used screencast software in educational settings and concludes with some practical guidelines for the effective implementation of screencast technology.
\end{abstract}

Keywords: Screencast video feedback, written feedback, technologymediated feedback 


\section{Introduction}

Feedback is an inseparable component of the English as a foreign language (EFL) writing classroom. It guides learners towards their learning goals by providing valuable information on their strengths and weaknesses (Cheng \& Li, 2020). Timely and appropriate feedback enables learners to achieve more and promotes a self-directed learning environment (Mahoney, Macfarlane \& Ajjawi, 2019). Feedback is particularly essential in the early stages of learners' writing courses since they encounter a 'threshold' in their writing (Adler-Kassner \& Wardle 2015). This can help learners become socialized and familiar with academic practices (Cavaleri, Kawaguchi, Di Biase, \& Power, 2019). Feedback can positively affect students' learning processes and maximize their effort. Feedback can make a big difference to students' writing that can be detected in their future work (ibid).

The traditional approach to feedback allows the teacher to provide a written commentary on students' work. This is teacher-written feedback that is often summative and is perceived as a focus-on-form approach (Yu, Jiang, $\&$ Zhou, 2020). This type of feedback is referred to as written corrective feedback (WCF) and is seen as the teacher's comments on students' written work. Written commentary can include praise, suggestion and criticism; it is often seen in the margins of students' assignments. Teachers mostly focus on the identification of students' linguistic errors and correcting them. WCF is one of the forms of asynchronous feedback. It is argued that such type of feedback is beneficial for students to realize their errors and correct their own mistakes (Arrad, Vinkler, Aharonov, \& Retzker, 2014). It is also believed that corrective feedback, as one of the crucial pedagogical practices, enhances students' writing skills. It can increase students' lexical range and grammatical accuracy (DeKeyser, 2007; Kang \& Han, 2016; Russell \& Spada, 2006). What is more, written feedback is perceived as thoughtful as students can easily read and realize teachers' feedback on their assignments (Parkin et al, 2012).

However, providing effective feedback has been a subject of research for decades because many research studies show that written feedback does not always achieve the purpose (Bush, 2020; Cunningham, 2019; Cunningham \& Link, 2021). Students often fail to understand and internalize the teacher's written feedback. They often perceive the teacher's feedback as impersonal, ambiguous and not focused on improvement (Crook et al. 2012; Douglas et al. 2016; Han \& Hyland 2019). Researchers argue that corrective feedback can have a negative effect on students' writing and may lead to questioning its effectiveness (Mao \& Crosthwaite, 2019; Shintani \& Ellis, 2013). What is more, many researchers' advocate abolishing WCF based on Truscott's (1996) argument according to which error correction does not result in the improvement of students' academic accuracy (Gad et al, 2016). It has been argued that the process of error correction is harmful and requires a huge 
amount of time and energy. Paradoxically, some studies reveal that corrective feedback often lacks details and explanation of errors identified by the teacher (McGrath \& Atkinson-Leadbeater, 2016). Corrective feedback is particularly disadvantageous for lower-level students since they may feel overwhelmed by the amount of written feedback (Mathieson, 2012; Lee 2014). Moreover, written feedback may be misunderstood or it rarely conveys the meaning the writer is trying to communicate (Cavaleri et al., 2019). Scattered comments in MS are also difficult to decipher and understand, for this reason, written feedback is often ignored.

Many scholars advocate using an alternative approach to written feedback in the form of audio and video recording (Anson, 2015, Cavaleri, Di Biase \& Kawaguchi, 2014). With the advances of technology, multimodal feedback has become the research area of many scholars in the EFL writing context. Deficiencies in written feedback encouraged educators to think of using different modes offered by technology in providing feedback. Expanding the pervasiveness of video and audio modes of technology increased access to screencast technology in education (Cunningham, 2019). Although limited research was done, the potential of the technology-mediated tool has been highlighted in motivating and engaging students in the feedback process (Stannard, 2008). Scholars argue that screencast technology is a promising approach to feedback offering a combination of aural and visual modes in which students can see their written work as well as listen to the teacher explaining it (Bush, 2020). Since the development of technology brought the necessity of electronic submission of students' work, teachers should also respond appropriately and provide feedback in the same way.

\section{Screencast video feedback}

Audio-visual feedback using screen-capture technology has widely become an alternative to traditional written corrective feedback. It is also referred to as screencasting. Screencasting is capturing one's actions performed on a computer screen through digital video recording (Cranny, 2016; Séror, 2013). The video is accompanied by a narration that can be recorded in the process of video creation. Recorded videos can then be shared as a web link or via email. The instructor can record his/her comments and guide students for revision (Russell, 2008). Video creation has become easier since it is accompanied by voice-over (Bakla, 2017). The technology has the potential of providing video feedback by combining two major modes: audio and visual. The purpose of screencast video feedback is to provide EFL writers clear and specific feedback on their assignments, indicate students' specific needs and discuss the approaches for revisions. The instructor may display the rubric and mark criteria that have or haven't been met (Whitehurst, 2021). Through this mode of feedback, students can see their written work and listen 
to the teacher's feedback; they can access the video feedback at any time and space (Cranny, 2016).

Scholars argue that screencast video feedback has conceptualized a new approach and contributed to the promotion of a self-directed, studentcentred environment (Cranny, 2016; Stannard, 2008, Cunningham \& Link, 2021). Recent studies have examined the effectiveness of using screencast video feedback in EFL writing. Research conducted by Cheng and Li (2020) compared feedback through screencast technology to text-only feedback in MS word. The findings of the study reveal that although there was no significant difference in the quantity of the teacher comments in each category, screencast video feedback focused more on content, whereas text-only feedback concentrated on grammar and language usage. A similar study was conducted by Ali (2016) who compared screencast video feedback with written feedback. The results showed that screencast video feedback was much liked and rated as multimodal and supportive by the participants. What is essential, the experimental group participants who received video feedback outperformed their counterparts in the control group at macro-level writing components. Screencast video feedback was also preferred by the participants in Cunningham's (2019) research that explored the efficiency of both types of feedback in L2 writing class. The participants found video feedback easily understandable and helpful for revising. It was also reported that video feedback had been efficient in terms of time.

Cunningham's (2019) research also suggests that screencast technology helps provide multimodal feedback since video feedback provides the teacher's spoken comments along with students' work on the screen. The instructor in his/her talk can gesture, highlight or show areas of work that she/he is commenting on. Due to it being multimodal, feedback is easy to follow and process information better (Anson 2015; Cavaleri et al. 2014; Stannard, 2008). This concept is theorized by Mayer's (2009) multimedia learning theory according to which the human brain is considered as a system of dual-channel and limited capacity. When information is presented in visual and audio mode, it minimizes the cognitive load and assists information processing better. In other words, the student can process feedback while it is delivered in dual-mode better than in a single mode only.

\section{Affordances of screencast video feedback}

One of the affordances of screencast video feedback can be seen through students' increased engagement in the feedback process. Bush (2020) argues that using screencast video feedback demonstrated higher student engagement in the writing process than written corrective feedback. The participants in the study seemed to have concentrated on video feedback and did not skip the video. Increased engagement in the feedback process was also 
reported in Ali's (2016) and Cranny's (2016) research studies. The scholars argue that increased engagement can partly be attributed to screencast technology due to being novel. Apart from novelty, students' engagement was determined by multimodal way of feedback given by the teacher (Bush, 2020). Through screencast video feedback, the instructor can underline, bold or apply highlighting strategies to provide clearer feedback (Bakla, 2017). Such strategies make it easier for the teacher to engage in a kind of dialogue with students, thus, promoting engagement and enhancing comprehension (Cranny, 2016). Gormely and McDermott (2011) also found screencast video feedback engaging and motivating. Since written feedback is often limited, screencast video enables the teacher to provide comprehensive audio feedback with the support of visual mode. Video feedback is also seen as more elaborated and detailed in Elola \& Oskoz's (2016) study that revealed students' increased engagement in a dialogue through feedback with the teacher.

The interpersonal relationship has also been noted as a benefit of screencast video feedback. Since video feedback is very conversational, students perceive it as personal and less formal (Anson, Dannels, Laboy \& Carneiro, 2016). Researchers argue that such a conversational style of feedback allows students to establish an interpersonal connection with the teacher (Ali, 2016; Anson et al., 2016). Students also reported screencast feedback to be encouraging, supportive and caring (ibid). Elola and Oskoz (2016) in their study of screencast video feedback found that the interpersonal nature of the feedback process increased instructors' awareness of video feedback as the form of interpersonal relations. Heightened awareness can contribute to the way feedback is formed and lead to differences in feedback perceived by students. Such differences can evoke greater respect and guidance compared to the written feedback (Cunningham \& Link, 2021). The study carried out by Cunningham (2017) explored key interpersonal differences between screencast video feedback and written comments provided in MS word. The findings of the study reveal that the comments given in MS word perceived the instructor as more authoritative whereas video feedback focused more on suggestions and advice that enabled students to preserve their autonomy. Cunningham and Link (2021) argue that the teacherstudent interpersonal relationship is essential since a large amount of language is learnt in the online environment. Asynchronous form of feedback is imperative in establishing an interpersonal relationship with students.

The use of video feedback can provide students with more flexibility than written feedback. Students can access feedback at any time and place; they can watch as many times as they wish, pause and rewind if needed (Cranny, 2016; Lee, 2017). Martinez (2016) argues that being flexible is functional especially for non-native speakers since comprehension may be an issue. They might pause a video, take down some notes or transfer feedback 
to their written work. This feature of screencast video feedback makes it a practical and essential tool to be applied in EFL writing. It can be efficient and improve the quality of communication. Video feedback is also easy to access from various devices (Cranny, 2016). Ducate and Arnold (2012) also report that the participants in their study watched the video several times while revising.

Apart from being communicative, screencast video feedback is thought to be time-saving (Yang and Carless, 2013). A 2-minute video feedback recording can accommodate about 400 written words or a whole sheet of A4 paper (Russel, 2008). Audio feedback can save the teacher's time in the circumstances when the teacher is familiar with the technology when she types or writes slowly or has to give a substantial amount of feedback (ibid).

\section{Challenges of using screencast video feedback}

Notwithstanding the above-mentioned affordances of video feedback, there are some challenges and pedagogical concerns associated with using screencast technology. One of the challenges can be students' emotional responses to video feedback. Listening to critical comments might be more painful than reading written commentary (Voelkel and Mello's study, 2014). Frustration may be noticeable in a tutor's voice that may lead to demotivating students (King, McGugan \& Bunyan, 2008). Students may feel nervous while watching the screencast, however, Bush (2020) believes it is fairly normal. The feeling of nervousness and uneasiness will be reduced when students become familiar with video feedback. The researcher argues that sometimes the teacher comments are not well-received by students, they may become annoyed while hearing negative comments, therefore, it is essential to hold "a pleasant demeanour" and give accurate feedback (Bush, 2020, p. 10).

Video feedback may also not be accessible to all types of learners. Depending on students' learning styles, audio-visual feedback may not be preferable for all types of learning styles. What is more, screencast video feedback may not be accessed by those students who have visual or learning impairments (Chalmers, MacCallum, Mowat \& Fulton, 2014; Johnson \& Cooke, 2015).

Screencast video feedback may also be challenging for teachers since they need to find appropriate time and space to record. Considering the teacher has to allocate some time to upload a video file, screencast video feedback practice cannot be viewed as time-saving (Ali, 2016). Although recording does not require much time, uploading or sharing may be time-consuming. Moreover, providing video feedback often happens outside working hours that may also pose another difficulty. Additionally, screencast video feedback does 
not allow editing; the concern of appearing a video file publicly is also expressed (King et al. 2008).

There might be some technical problems in creating and viewing screencast videos. A video format can be one of the issues; a video recorded by the teacher may not open on some devices, therefore, posing a challenge for learners (Bakla, 2017). The scholar argues that teachers should use common formats and share the video through email or cloud storage. Another problem may be a low sound quality that can impact video feedback quality. Background sound can also distract learners and lead them to dislike video feedback (Lee, 2017). In-built microphones and up-to-date computer systems might be available to offer better quality recording.

\section{Implications of screencast video feedback on EFL writing}

The above-described affordances and research studies reveal that screencast video feedback can greatly impact EFL writers. Screencast video feedback is less overwhelming for students with many grammatical errors because the teacher comments through screencast tend to focus on content, structure and organization of students' written work (Elola \& Oskoz, 2016). This type of feedback is particularly useful to improve high order thinking skills (Ali, 2016; Ducate \& Arnold, 2012) and is beneficial for dyslexic learners (Harper, Green, \& Fernandez-Toro, 2015). Moreover, screencast video feedback appeals to visual and auditory learners and provides an opportunity to practise listening along with writing skills (Ali, 2016; Harper et al., 2015).

Cunningham (2017) argues that due to fact that screencast video feedback is clear, specific, engaging and motivating (Ali, 2016; Elola \& Oskoz, 2016; Harper, Green, \& Fernandez-Toro, 2015), many feedbackrelated issues could be overcome. Video feedback leads instructors to give more explanations on students' written work thus encouraging revision. Successful revising in return can lead to writing skill improvement (Ali, 2016). Although written feedback offers quicker and more precise error correction, Elola \& Oskoz (2016) argue that with video feedback students have a higher rate of success in local revision. The findings of the study conducted by Elola \& Oskoz (2016) reveal that video feedback can be effective for revision and successful at addressing linguistic errors.

Despite being personal and conversational, screencast video feedback makes EFL writers more comfortable than face-to-face situations since the letter creates a social presence of the teacher (Vincelette \& Bostic, 2013). The fact that instructors are not facing students eliminates social pressure and makes feedback more accurate and adept at commenting. In other words, screencast video enables social interaction without the strong social pressure of the teacher. This one-way delivery is thought to invite shared discussion 
since students can respond to feedback or make a list of follow-up conversations with the teacher. Vincelette and Bostic (2013) argue that screencast feedback initiates a dialogue and leads to more articulated writing; it establishes an alternative assessment that allows for optimal growth in EFL writing. Ice et al. (2007) also claim that audio feedback is personalized that has an impact on students' writing practices.

Many research studies explored EFL writers' perception of the effectiveness of screencast video feedback (Elola \& Oskoz, 2016; Vincelette, 2013; Ice et al, 2010). Scholars claim that students' perception is positive stemming from the desire for multi-sensory feedback. In other words, students prefer multimodal feedback and perceive them as more valid and accurate than written comments. Whitehurst (2021) claims that screencast videos can receive an overwhelming amount of positive feedback from students. It enables students to realize how specific errors can impact their writing scores. Screencast video feedback can provide more explanation on specific errors, however, it is also thought that it may not necessarily address the problem (Vincelette \& Bostic, 2013).

\section{Overview of screencast software}

There are several free and low-cost screencast software that can be used in providing video feedback on students' written work. When choosing the software, it is essential to be user-friendly and easy to use. There are a few alternatives that have recently gained popularity in education.

Camtasia is one of the top-rated screen recorders and video editors; it is quick and easy to use with no video editing skills required. It can create high quality, interactive videos that can catch the listener's attention. Camtasia is ideal for video lessons, meetings or webinar recordings. The instructor can record screen- websites, video calls or PowerPoint presentations. The built-in video editor allows the teacher to add effects such as arrows or texts. The recorded video can easily be uploaded on YouTube, Video or Screencast. Teachers can add a personal touch to their screencast by adding video from their webcam. Camtasia is not free, but once paid, it gives lifetime access. It offers a 30-day free trial (TechSmith.com).

Screencast-O-Matic is another alternative that can easily record and edit videos. It is widely used in education for flipped/blended learning; it is popular for easy and quick communication. As of July 2021, Screencast-OMatic is used in 190 countries with more than 60000000 captured screens already (Screencast-o-matic.com). Screencast-O-Matic is a free tool that can easily capture the screen, add a webcam or narration. The video editor allows personalizing videos, such as adding texts, shapes or images. The instructor can also use automated captions and many more features. Video editing is not included in the free package; it comes with deluxe or premier paid accounts. 
Snagit is one of TechSmith's low-cost screen capture software. It is widely used in education and employment; it allows quick screencasts with additional contexts and easy share of the recorded video. Built-in library with lifetime access enables to keep all videos and images sorted. Snagit allows capturing full screen or a scrolling screenshot. It can simply grab vertical and horizontal scrolls and long chat messages or anything that comes in between. As with other tools described above, Snagit also allows toggling between webcam and screen capture. Recorded videos can be trimmed or annotated with professional mark-up tools. Snagit is not free but it is one of the low-cost screencast tools (TechSmith.com)

TechSmith Capture (formally known as Jing) is a free screen capture software, and it enables the teacher to create basic screen recordings. It offers many features such as longer video and audio recording, full screen or cropped image capture, simple annotation tools and easy upload to TechSmith account. The software is easy to use and is ideal for teachers who would like to start making screencast video feedback.

\section{Implementing screencast video In EFL classroom}

As screencast feedback requires a huge amount of time, it is advisable to use the tool for high-stakes process assignments, e.g., essays (Whitehurst, 2021). To manage the teacher workload, it is advisable to provide video feedback for those assignments that weigh more in the overall class grade. The goal of the teacher should be to allow students to revise and succeed in their writing. Whitehurst (2021) enumerates a few steps to follow to provide video feedback. Firstly, it is essential to familiarize with the student's paper and make notes that the instructor would like to highlight in the video. The teacher can open and minimize the assignment rubric, the assignment itself or any relevant resources that can be referred to in the video. During recording, the teacher needs to start with positive reinforcement such as greeting and identification of skills that were executed well in the assignment. Next, the teacher can identify the areas that need to be improved. It is essential to focus on the error pattern rather than all errors and demonstrate how to correct them. The teacher can show specific examples or locate the student's errors on the assignment rubric. On the rubric, the teacher can indicate the criteria that have or haven't been met. As a recommendation, the teacher can provide the student with resources or websites to help improve those identified skills. Lastly, the teacher can give the concluding remarks and finish the recording with a positive note by showing gratitude. Figure 1 illustrates the suggested framework on how to record screencast video feedback. 
Figure 1: The process of screencast video recording

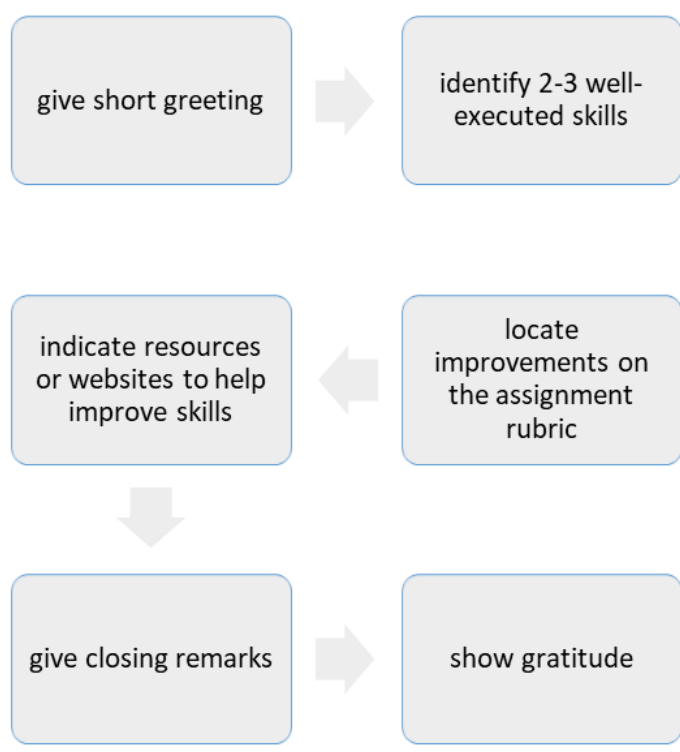

identify 2-3 skills that need to be improved

show specific examples

Source: adapted from Whitehurst (2021).

After the completion of the recording, the video can be saved as an MP4 or uploaded on the screencast website. The teacher can send an email to students or share the link through the learning management system with the screencast video attached. The video can easily be opened on all devices and in case the student experiences a problem of viewing, the teacher can further assist them. The video can also be shared through internet cloud services. It is also possible to upload the file on YouTube with private access which allows only selected users to view the video (Whitehurst, 2021).

\section{Conclusion}

The above-given overview of screencast video feedback has demonstrated that notwithstanding some drawbacks, oral feedback presents educators with a new, $21^{\text {st }}$-century, multimodal opportunity of feedback provision. Since technology-mediated learning has dominated all educational settings, it is impossible to ignore its implication on learning. Screencast video technology offers a two-dimensional video communication between the teacher and the student. The teacher-student interpersonal relationship enhances language learning (Cunningham and Link, 2021). What is more, with screencast video feedback the absence of the social pressure of the teacher allows students to feel more comfortable with their writing (Vincelette \& Bostic, 2013). The above-described research studies have also demonstrated that screencast video feedback is accessible and more flexible since students can watch it at any time (Cranny, 2016; Lee, 2017). More importantly, 
screencast video feedback encourages students to revise their writing assignments and improve on their mistakes (Cunningham, 2017). It can successfully address linguistic errors and enable students to succeed in local revision (Elola \& Oskoz, 2016). Since some studies show that written feedback offers quicker and more precise error correction, a combination of screencast video feedback and written feedback is suggested. However, it seems that screencast technology will more actively be incorporated in teaching and learning practices. It has so far proved to be one of the effective tools for giving feedback in EFL writing classes.

\section{References:}

1. Adler-Kassner, L \& Wardle, E. (2015). Naming what we know: Threshold concepts of writing studies. Utah State University Press, Boulder, Colorado.

2. Ali, A. (2016). Effectiveness of using screencast feedback on EFL students' writing and perception. English Language Teaching, 9(8), 106-121.

3. Anson, C. M., Dannels, D. P., Laboy, J. I., \& Carneiro, L. (2016). Students' perceptions of oral screencast responses to their writing: Exploring digitally mediated identities. Journal of Business and Technical Communication, 30(3), 378-411. https://doi.org/10.1177/1050651916636424.

4. Anson, I. (2015). Assessment feedback using screen-capture technology in political science. Journal of Political Science Education, 11(4), 375-390.

5. Arrad, G., Vinkler, Y., Aharonov, D., \& Retzker, A. (2014). Increasing sensing resolution with error correction. Physical Review Letters, 112(15), 1-14

6. Bakla, A. (2017). An Overview of Screencast Feedback in EFL Writing: Fad or the Future? In International Foreign Language Teaching and Teaching Turkish as a Foreign Language, (pp. 319331), Bursa, Turkey.

7. Bush, J. C. (2020). Using Screencasting to give feedback for academic writing. Innovation in Language Learning and Teaching, 1-14. https://doi.org/10.1080/17501229.2020.1840571.

8. Cavaleri, M., Di Biase, B. \& Kawaguchi, S. (2014). Academic literacy development: Does video commentary feedback lead to greater engagement and response than conventional written feedback? International Journal of Literacies, 20(3), 19-38.

9. Cavaleri, M., Kawaguchi, S., Di Biase, B., \& Power, C. (2019). How recorded audio-visual feedback can improve academic language 
support. Journal of University Teaching \& Learning Practice, 16(4), $1-19$.

10. Chalmers, C., MacCallum, J., Mowat, E. and Fulton, N. (2014). Audio feedback: Richer language but no measurable impact on student performance. Practitioner Research in Higher Education, 8(1), 64-73.

11. Cheng, D., \& Li, M. (2020). Screencast video feedback in online TESOL classes. Computers and Composition, 58, 1-17.

12. Cranny, D. (2016). Screencasting, a tool to facilitate engagement with formative feedback? All Ireland Journal of Teaching and Learning in Higher Education, 8(3), 2911-2938.

13. Crook, A., Mauchline, A., Maw, S., Lawson, C., Drinkwater, R., Lundqvist, K., Orsmond, P., Gomez, S. \& Park, J. (2012). The use of video technology for providing feedback to students: Can it enhance the feedback experience for staff and students? Computers and Education, 58(1), 386-396.

14. Cunningham, K. J. (2017). Appraisal as a framework for understanding multimodal electronic feedback: Positioning and purpose in screencast video and text feedback in ESL writing. Writing \& Pedagogy, 9(3), 457-485. https://doi.org/10.1558/wap.31736.

15. Cunningham, K. J. (2019). Student perceptions and use of technologymediated text and Screencast feedback in ESL writing. Computers and Composition, 52, 222-241.

16. Cunningham, K. J., \& Link, S. (2021). Video and text feedback on ESL writing: Understanding attitude and negotiating relationships. Journal of Second Language Writing, 52, 1-17. https://doi.org/10.1016/j.jslw.2021.100797

17. DeKeyser, R. (Ed.). (2007). Practice in a second language: Perspectives from applied linguistics and cognitive psychology. Cambridge University Press.

18. Douglas, T., Salter, S., Iglesias, M., Dowlman, M. \& Eri, R. (2016). The feedback process: Perspectives of first and second year undergraduate students in the disciplines of education, health science and nursing. Journal of University Teaching and Learning Practice, 13(1), 1-19

19. Ducate, L. \& Arnold, N. (2012). Computer-mediated feedback: Effectiveness and student perceptions of screen-casting software versus the comment function. In G. Kessler, A. Oskoz, \& I. Elola (Eds.), Technology Across Writing Contexts and Tasks (vol. 10) (pp. 31-56). San Marcos, TX: CALICO.

20. Elola, I., \& Oskoz, A. (2016). Supporting Second Language Writing Using Multimodal Feedback. Foreign Language Annals, 49(1), 58-74. 
21. Gad, E. E., Li, Y., Kliewer, J., Langberg, M., Jiang, A. A., \& Bruck, J. (2016). Asymmetric error correction and flash-memory rewriting using polar codes. IEEE Transactions on Information Theory, 62(7), 4024-4038.

22. Gormely, K., \& McDermott, P. (2011). Do you Jing? How screencasting can enrich classroom teaching and learning. Language and Literacy Spectrum, 21, 12-20.

23. Han, Y. \& Hyland, F. (2019). Learner engagement with written feedback: A sociocognitive perspective. In K. Hyland \& F. Hyland (eds), Feedback in Second Language Writing: Contexts and Issues (pp. 247-264). Cambridge University Press, Cambridge, England.

24. Harper, F., Green, H., \& Fernandez-Toro, M. (2015). Using screencasts in the teaching of modern languages: Investigating the use of Jing in feedback on written assignments. The Language Learning Journal, 1-18. doi:10.1080/09571736.2015.1061586

25. Ice, P., Curtis, R., Phillips, P., \& Wells, John. (2007). Using asynchronous audio feedback to enhance teaching presence and student sense of community. Journal of Asynchronous Learning Networks, 11(2), 3-25.

26. Ice, P., Swan, K., Diaz, S., Kupczynski, L., \& Swan-Dagen, A. (2010). An analysis of students' perceptions of the value and efficacy of instructors auditory and text-based feedback modalities across multiple conceptual levels. Journal of Educational Computing Research, 43(1), 113-134.

27. Johnson, G.M. \& Cooke, A. (2015). Self-regulation of learning and preference for written versus audio-recorded feedback by distance education students. Distance Education, 37(1), 1-14.

28. Kang, E., \& Han, Z. (2015). The efficacy of written corrective feedback in improving L2 written accuracy: A meta-analysis. The Modern Language Journal, 99(1), 1-18.

29. King, D., McGugan, S., \& Bunyan, N. (2008). Does it make a difference? Replacing text with audio feedback. Practice and Evidence of Scholarship of Teaching and Learning in Higher Education, 3(2), 145-163.

30. Lee, I. (2014). Revisiting teacher feedback in EFL writing from sociocultural perspectives. TESOL Quarterly, 48(1), 201-213.

31. Lee, I. (2017). Classroom writing assessment and feedback in L2 school contexts. Singapore: Springer Nature Singapore.

32. Mahoney, P., Macfarlane, S., \& Ajjawi, R. (2019). A qualitative synthesis of video feedback in higher education. Teaching in Higher Education, 24(2), 157-179. http://dx.doi.org/10.1080/13562517.2018.1471457 
33. Mao, S. S., \& Crosthwaite, P. (2019). Investigating written corrective feedback: (Mis)alignment of teachers' beliefs and practice. Journal of Second Language Writing, 45, 46-60

34. Martinez, R. (2016). Screencasting feedback on student essays. Retrieved 19 July 2021 from https:// www.facultyfocus.com/articles/teaching-with-technologyarticles/flipping-feedbackscreencasting-feedback-on-student-essays/

35. Mathieson, K. (2012). Exploring student perceptions of audiovisual feedback via screencasting in online courses. American Journal of Distance Education, 26(3), 143-156.

36. Mayer, R.E. (2009). Multimedia learning ( $2^{\text {nd }}$ ed). Cambridge University Press, New York.

37. McGrath, A. \& Atkinson-Leadbeater, K. (2016). Instructor comments on student writing: Learner response to electronic written feedback. Transformative Dialogues, 8(3), 1-16.

38. Parkin, H., Hepplestone, S., Holden, G., Irwin, B., \& Thorpe, L. (2012). A role for technology in enhancing students' engagement with feedback. Assessment and Evaluation in Higher Education, 37(8), 963-973.

39. Russell, J., \& Spada, N. (2006). The effectiveness of corrective feedback for the acquisition of L2 grammar. In J. M. Norris \& L. Ortega (Eds.), Synthesizing Research on Language Teaching and Learning (pp. 133-146). Benjamins.

40. Screencast-o-matic.com (2021). Capture, create, share. Retrieved 19 July 2021 from https://screencast-o-matic.com/

41. Séror, J. (2013). Show me! Enhanced feedback through Screencasting technology. TESL Canada Journal, 30(1), 104-116.

42. Shintani, N., \& Ellis, R. (2013). The comparative effect of direct written corrective feedback and metalinguistic explanation on learners' explicit and implicit knowledge of the English indefinite article. Journal of Second Language Writing, 22(3), 286- 306.

43. Silva, M. L. (2012). Camtasia in the classroom: Student attitudes and preferences for video commentary or Microsoft Word comments during the revision process. Computers and Composition, 29, 1-22. http://dx.doi.org/10.1016/j.compcom.2011.12.001Simonsson

44. Stannard, R. (2008). Screen capture software for feedback in language education. In M. Thomas (ed.) Proceedings of the Second International Wireless Ready Symposium Interactivity, Collaboration and Feedback in Language Learning Technologies, (pp. 16-20) NUCB Graduate School Michael Thomas.

45. TechSmith.com (2021). TechSmith products. Retrieved 19 July 2021 from https://www.techsmith.com/products.html 
46. Truscott, J. (1996). The case against grammar correction in L2 writing classes. Language Learning, 46(2), 327-369.

47. Vincelette, E. J. \& Bostic, T. (2013). Show and tell: Student and instructor perceptions of screencast assessment. Assessing Writing, 18, 257-277. http://dx.doi.org/10.1016/j.asw.2013.08.001.

48. Vincelette, E. J. (2013). Video capture for grading: multimedia feedback and the millennial student. In E. Smyth, \& J. Volker (Eds.), Enhancing Instruction with Visual Media: Utilizing Video and Lecture Capture (pp. 107-127). Hershey, PAIGI-Global.

49. Voelkel, S. and Mello, L.V. (2014). Audio feedback-better feedback? Bioscience Education, 22(1), 16-30.

50. Whitehurst, J. (2021). Screencast feedback for clear and effective revisions of high-stakes process assignments. Retrieved 26 July 2021 from https://cccc.ncte.org/cccc/owi-open-resource/screencastfeedback

51. Yang, M. and Carless, D., (2013). The feedback triangle and the enhancement of dialogic feedback processes. Teaching in Higher Education, 18(3), pp.285-297.

52. Yu, S., Jiang, L., \& Zhou, N. (2020). Investigating what feedback practices contribute to students' writing motivation and engagement in Chinese EFL context: A large scale study. Assessing Writing, 44, 115. 